\title{
New particle formation by ion-induced nucleation during dissipation stage of thunderstorm
}

\author{
S D Pawar, P Murugavel and V Gopalakrishnan* \\ Indian Institute of Tropical Meteorology, Pune, India. \\ ${ }^{*}$ Corresponding author. e-mail: gopal@tropmet.res.in
}

\begin{abstract}
A case of new particle formation observed during dissipation stage of a thunderstorm at a tropical station, Pune, India on 3 June 2008 is reported. The flash rate and rainfall intensity increased as high as 110 flashes per 5 minutes and $150 \mathrm{~mm}_{\text {hour }}{ }^{-1}$ respectively during the active stage of thunderstorm, and then gradually decreased during the dissipation stage. The number concentration of particles in the size range of 10-100 $\mathrm{nm}$ sharply increased from 350 particles $\mathrm{cm}^{-3}$ to $\sim 8000$ particles $\mathrm{cm}^{-3}$ during the dissipation stage of a thunderstorm and grew to larger diameter subsequently. Observations suggest that the atmospheric conditions such as (i) reduced background aerosol concentration after heavy rain, (ii) high humidity condition, and (iii) increased ion concentration during the dissipation stage by corona discharges, favoured generation of new particles by ion-induced nucleation (IIN). Observations also suggest that generation of unipolar ions by corona discharges may be more favourable for IIN and subsequent growth of the particles.
\end{abstract}

\section{Introduction}

Events of aerosol nucleation have been observed at various parts of the world at different atmospheric conditions. The mechanism and atmospheric conditions controlling the onset of such events are not yet clearly understood. The gas-to-particle conversion (GPC) process, in which small clusters of molecules form through binary homogeneous nucleation of sulphuric acid and water and subsequently grow to particles larger than $3 \mathrm{~nm}$, could not alone explain the nucleation rates observed at various parts of the world (Kulmala et al 2004). Wilson (1895) had shown for the first time that increased ionization could trigger the process of new particle formation. Cluster ions can grow to form new particles and rate of such new particle formation will be proportional to ion concentration or the ionization rate in the atmosphere (Dickinson 1975). Later, many studies have identified ioninduced nucleation (IIN) as one of the most important source of atmospheric particles at some locations. Laakso et al (2002) have suggested that new particle formation by IIN process can occur under some favourable atmospheric conditions, like low temperature, high relative humidity, high ion production rate, and low concentrations of preexisting particles. The findings of Lee et al (2003) indicate that, at upper troposphere and lower stratosphere, because of favourable conditions such as relatively high ion-production rates by galactic cosmic rays, low temperatures, and relatively low surface areas of pre-existing aerosols, ioninduced nucleation process is a dominant process for new particle formation. Yu (2006) has demonstrated using a kinetically consistent ion-mediated

Keywords. New particle formation; ion-induced nucleation; lightning intensity and rain. 
nucleation model that ions can lead to significant particle formation not only in the upper troposphere but also in the lower troposphere including boundary layer.

Here we present an event of new particle formation observed in the dissipation stage of a thunderstorm. Role of increased ionization during dissipation stage of thunderstorm due to point discharges have also been discussed.

\section{Observatory, instrumentation and data}

The Atmospheric Electricity Observatory is situated at Pune $\left(18^{\circ} 32^{\prime} \mathrm{N}, 73^{\circ} 51^{\prime} \mathrm{E}, 573 \mathrm{~m}\right.$ AMSL), India, on the lee side of the Western Ghats about $100 \mathrm{~km}$ inland from the west coast of India. Measurements of atmospheric electric field, Maxwell current density, aerosol size-distribution, rain intensity and rate, along with meteorological parameters such as temperature, humidity, wind speed and direction are being made at the surface level in this observatory.

Atmospheric electric field (E) is measured by a vertical field mill as described by Kamra and Pawar (2007). The time constant of the field mill is adjusted to $0.1 \mathrm{~s}$. The field mill can measure the electric field in the range $\pm 15 \mathrm{kV} / \mathrm{m}$ and the response of the field mill in this range is found to be linear during the calibration. The sensitivity of the field mill is $\pm 2 \mathrm{~V} / \mathrm{m}$ and the noise level is well below $\pm 2 \mathrm{~V} / \mathrm{m}$. Aerosol number concentration and size-distributions in the mid-point diameter range of $3-113 \mathrm{~nm}$ have been measured using a Scanning Mobility Particle Sizer (SMPS, Model 3936, TSI Inc., USA). The SMPS sequentially scans for each channel starting from 3 to $113 \mathrm{~nm}$ using a differential mobility analyser (DMA). Even though SMPS has the ability to measure particles down to $3 \mathrm{~nm}$ size, the transfer function (the probability that a particle of electrical mobility $Z p$ entering the DMA, will exit the DMA in a given monodisperse aerosol flow without diffusion loss) used in this measurement derived by Knutson and Whitby (1975) and this equation do not account for diffusion losses. This is very critical in smaller particles size even in the fully developed laminar flow. It has been shown that diffusion losses and broadening of transfer function can create large uncertainty, especially, in the lower size bins of measurements (Kousaka et al 1985; Mamakos et al 2007). Therefore, we have used particles above $10 \mathrm{~nm}$ size in this study. Time resolved sizespectra of rain drops from $0.3-20 \mathrm{~mm}$ diameter sizes is measured by a disdrometer (OTT Parsivel, Germany) and the rain rate and intensity are calculated from this spectrum.

\section{Results}

A thunderstorm developed in the vicinity of our observatory at about 1600 hrs local time (LT) on June 3, 2008 and lasted for about 2 hours. Figure 1 shows the meteorological parameters observed on that day during the thunderstorm period. The winds which were initially about $5 \mathrm{~m} \mathrm{sec}^{-1}$ increased to $10-15 \mathrm{~m} \mathrm{sec}^{-1}$ during active stage and again decreased to less than $3 \mathrm{~m} \mathrm{sec}^{-1}$ at about $1800 \mathrm{hrs}$ LT in the dissipation stage. Air temperature sharply decreased by about $10^{\circ} \mathrm{C}$ during the thunderstorm period and relative humidity was more than $90 \%$. As shown in the figure 2 (a), with the onset of thunderstorm, electric field increased to $2 \mathrm{kVm}^{-1}$ and lightning activity started at about $1620 \mathrm{hrs}$. The flash rate and rain intensity are shown in figure 2(b). Lightning flash rate increased very rapidly, reached to 120 flashes per 5 minutes during active stage of thunderstorm, and then decreased gradually to less than one flash per 5 minutes at about 1800 hrs. Precipitation started at about $1700 \mathrm{hrs}$ LT and the rain intensity sharply increased to $150 \mathrm{~mm} \mathrm{hr}^{-1}$ in the active stage of thunderstorm and then decreased gradually to $3 \mathrm{~mm} \mathrm{hr}^{-1}$ in the dissipation stage, at about $1800 \mathrm{hrs}$ LT (figure 2b). The total aerosol concentration along with 5-minute average of electric filed is shown in figure 2(c). The concentration of aerosols decreased from about 2000 particles $\mathrm{cm}^{-3}$ just before the start of thunderstorm to less
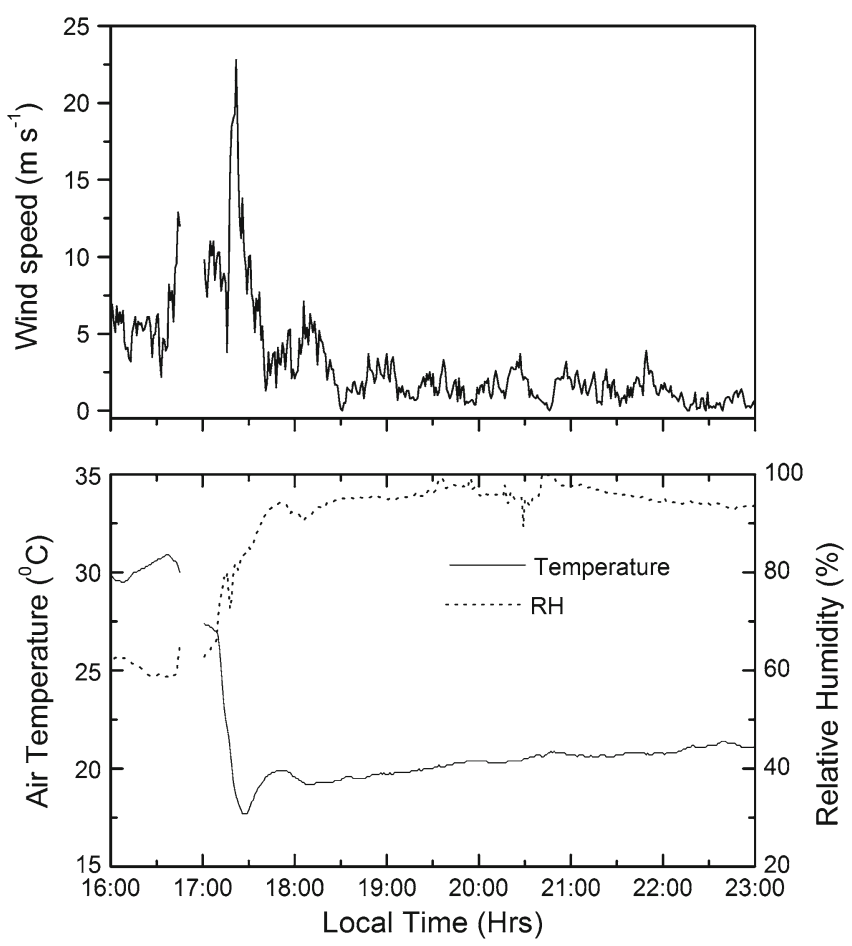

Figure 1. Plots of temperature, humidity and wind speed during the thunderstorm on June 3, 2008. 


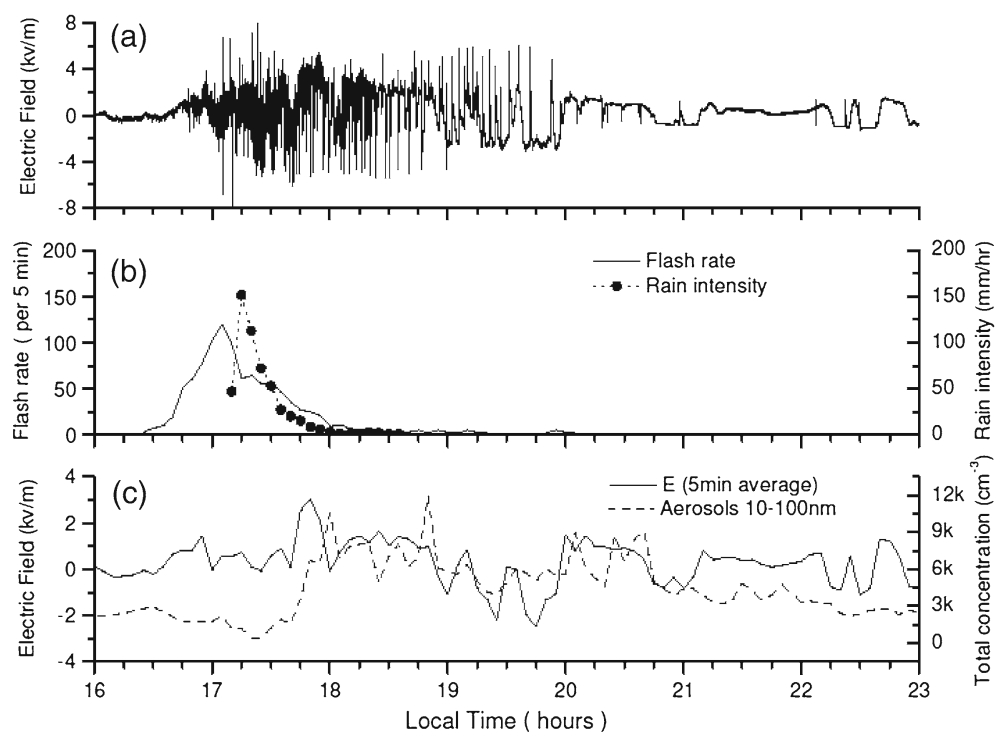

Figure 2. Variations of (a) electric field, (b) lightning flash rate and rainfall intensity, and (c) 5-minute averaged electric field along with total concentration of aerosols in the size range 10-100 nm during the period of thunderstorm.

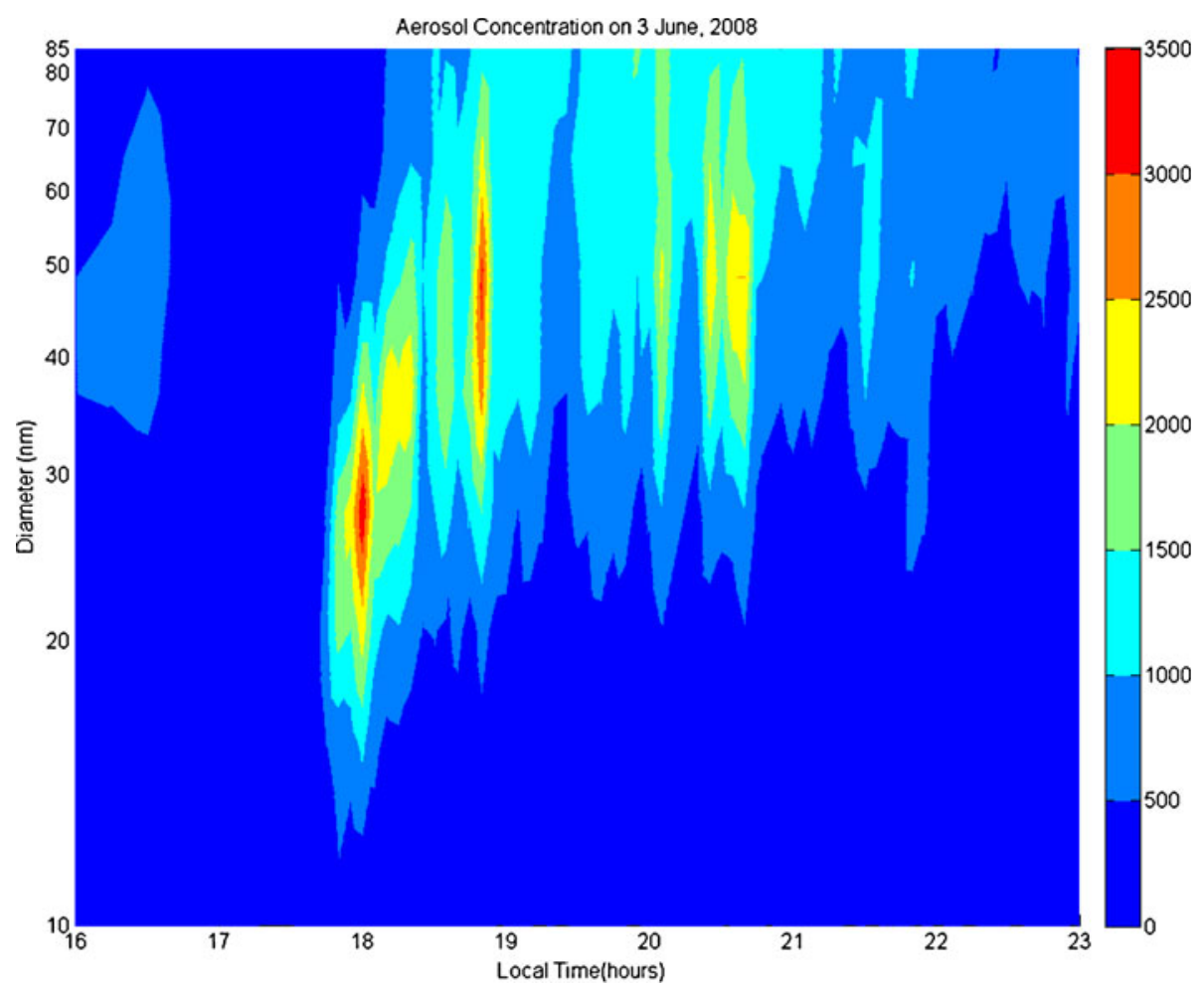

Figure 3. Temporal variation of aerosol number-size distribution during the thunderstorm period.

than 500 particles $\mathrm{cm}^{-3}$ during heavy precipitation. Sudden increase in aerosol concentration was observed with the cessation of rainfall, at about 1800 hrs (figure 2c). Figure 3 shows the time evolution of size distributions of aerosols during this thunderstorm. Removal of all sizes of aerosols by precipitation during active stage of thunderstorm can be seen clearly in this figure. Sudden burst in ultrafine mode particles at $1800 \mathrm{hrs} \mathrm{LT}$ and subsequent growth of these particles also can be seen. It should be mentioned here that less particle concentration in the size range $10-20 \mathrm{~nm}$, might be due to diffusion losses as explained by Mamakos et al (2007). The average growth rate from 1800 to $1900 \mathrm{hrs}$ LT was about $20 \mathrm{~nm} /$ hour, which decreased sharply after $1900 \mathrm{hrs}$ LT. As can be seen in figure 3 , the growth rate in the first half an hour was as high as about $35 \mathrm{~nm} /$ hour and such 
a high growth rate has been reported very rarely. Kulmala et al (2004) have reviewed the cases of new particle formation all over the world. As they have shown, the growth rates lie between 1 and $20 \mathrm{~nm} / \mathrm{hr}$ in most of the places. However, O'Dowd et al (2002), over the western coast of Ireland, have reported growth rate as high as $200 \mathrm{~nm} / \mathrm{hr}$.

Another case of new particle formation was observed during a thunderstorm on June 4, 2008. On June 4, 2008, a thunderstorm was developed near to our observatory at about 1530 hrs LT. This thunderstorm was not as severe as on June 3, 2008. Lightning frequency was less initially at $1550 \mathrm{hrs}$ LT, became intense and increased up to 27 lightning flashes per 5 minutes at about $1700 \mathrm{hrs}$ LT and decreased gradually in dissipation stage at about 1720 hrs LT. Precipitation started at about $1650 \mathrm{hrs}$ LT and rain intensity increased to $15 \mathrm{~mm} \mathrm{hr}^{-1}$ in the active stage of thunderstorm and then decreased gradually in the dissipation stage at about 1720 hrs LT. Figure 4 shows the time evolution of size distribution of aerosols during this thunderstorm. As shown in this figure, there was sudden increase of ultrafine mode particles at about $1720 \mathrm{hrs}$ LT just after dissipation stage. It can be seen from figure 4 , the subsequent growth of the ultrafine particles into higher diameter; however, the growth rate is not as high as observed in case of thunderstorm observed on June 3, 2008 (figure 3).

\section{Discussion}

The electric field at the tip of sharp, grounded and elevated objects below thunderstorms can be as high as many hundred times than that of the ambient electric field. If the magnitude of the ambient electric field exceeds a few $\mathrm{kV} \mathrm{m}^{-1}$, it produces electrical discharges at the tip of elevated objects known as coronae discharges. Livingston and Krider (1978) and Krider and Musser (1982) have shown that due to frequent lightning, time averaged electric field and hence corona current could be very small during active phase of thunderstorm. However, in the dissipation stage, time averaged electric field value becomes high because of reduced lightning frequency, which enhances the corona current. Pawar and Kamra (2009) have shown that the space charge released into the atmosphere by corona currents from the ground can increase the air-conductivity of the atmosphere near to earth surface by more than an order of magnitude during the dissipation stage of thunderstorm.

Our observations clearly show an event of new particle formation and subsequent growth of those particles (figure 3). Since ion production rate determines the amount of ions available for nucleation, it has been considered as the main factor for initiation of ion-induced nucleation. Even though measurement of ions was not made during this thunderstorm, earlier observations of Pawar and Kamra (2009) at this place and at many other places (e.g., Standler and Winn 1979; Standler 1980; Livingston and Krider 1978; Krider and Musser 1982) clearly suggest increase in ionization rate by almost an order, near to earth surface during dissipation stage. It should be noted here that maximum value of averaged electric field has reached more than $+3 \mathrm{kV} / \mathrm{m}$ just before the start of this event. Laakso et al (2002) have shown that some favourable conditions, like low temperature, high relative humidity $(\mathrm{RH})$, high ion production rate, and low concentrations of pre-existing particles are essential to initiate ion-induced nucleation process. As shown in figure 2(c), the background aerosol concentration has reduced to a very low value due to heavy rainfall just before the start of this nucleation event. In addition, as shown in figure 1, higher humidity of about $90 \%$ and low temperature prevailed during this event. Under such favourable atmospheric conditions, the observed new particle formation can be attributed to ionnucleation process. New particle formation events cannot be observed unless the source rate of condensable vapours is sufficiently high (Kulmala et al 2004). Murugavel and Chate (2009) have estimated the concentration of vapour and its source rate at this location and have found that the values are high enough to trigger the nucleation bursts.

In our observation, electric field was of positive polarity at the time when new particle event was observed. Therefore, ions released in the atmosphere due to corona discharges should be of positive polarity. Some studies suggest that the negative ions, rather than positive ions contribute significantly to ion-induced nucleation process. However, measurements made by Hirsikko et al (2007), Arnold (2008) and laboratory experimental study by Rabeony and Mirabel (1987) suggest that positive and negative ions contribute almost equally to new particle formation. It should be noted here that during the processes of corona discharge, unipolar ions are released in the atmosphere. Arnold (2008) has shown that ion concentration depends on ion production rate and the ion-ion recombination coefficient $\left(N=(Q / \alpha)^{1 / 2}\right)$, where $Q$ is ionization rate and $\alpha$ is ion-ion recombination coefficient). Enghoff and Svensmark (2008) have also shown that ion nucleation process is not limited by the ion production rate, however the limiting factor is the rate of cluster production relative to the loss rate of ions by recombination and scavenging by larger clusters. In the case of unipolar ion generation, recombination coefficient 
$\alpha$ would be negligible compared to bipolar ionization because of very low concentration of other polarity ions. In addition, the lifetime of cluster ions can be higher in such unipolar ion environment than in normal environment. The increase in life time of cluster ions can increase the growth rate of new particles. Higher growth rate of $35 \mathrm{~nm}$ per hour observed by us in first half an hour of new particle formation event is significantly higher than the values reported earlier by Kulmala and Kerminen (2008).

Kulmala et al (2004) have reported that the growth rate lies in the range of $1-10 \mathrm{~nm} \mathrm{~h}^{-1}$. Some cases of growth rates as small as $0.1-1.0 \mathrm{~nm}$ $\mathrm{h}^{-1}$ have been observed in remote locations (e.g., Vehkamäki et al 2004), whereas growth rate larger than $10 \mathrm{~nm} \mathrm{~h}^{-1}$ has been reported in polluted environments (Kulmala et al 2005; Laaksonen et al 1995; Stolzenburg et al 2005; Hamed et al 2007; Wu et al 2007). Very high growth rates in excess of $100 \mathrm{~nm} \mathrm{~h}^{-1}$ can be reached in plumes and in coastal zones intermittently (e.g. O'Dowd et al 2007). Our observation of growth rate of $35 \mathrm{~nm} \mathrm{~h}^{-1}$ cannot be explained by conventional nucleation process and needs some other mechanism as proposed by us.

Another case of observation of new particle formation occurred on June 4, 2008 is not as systematic as observed on June 3, 2008, as shown in figure 4. However, we do observe abrupt increase in ultrafine particles and their subsequent growth into bigger diameters. This increase in ultrafine particles was observed in the dissipation stage of thunderstorm when lightning frequency reduced and electric field was high. These observations (figure 4) strengthen our hypothesis that low background aerosol concentration due to washout by rain and increased ion concentration due to corona discharges during dissipation stage of thunderstorm can trigger new particle formation via ion nucleation process.

Increase in concentration of particles less than $50 \mathrm{~nm}$ during dissipation stage is a common occurrence in thunderstorms observed in Pune. One such case is plotted in figure 5 where time evolution of electric field and aerosol concentration particles below $50 \mathrm{~nm}$ observed during a thunderstorm on May 22, 2008. As shown in figure 5, the particle concentration, which was about 3000 particles per $\mathrm{cm}^{3}$ before thunderstorm, reduced to 1500 particles per $\mathrm{cm}^{3}$ after the start of precipitation and increased sharply during the dissipation stage of thunderstorm. Such observations clearly suggest that the process of new particle formation occurs below thundercloud when conditions such as low background aerosols and high ion concentrations are fulfilled. The newly formed particles can increase the aerosol concentration in the surrounding area.
It should be noted here that both the cases of new particle formation presented here occurred during evening time when sun radiation is less. Ayers et al (1980) have pointed out that because of its low vapour pressure, generally nucleation is initiated by sulfuric acid. Further as $\mathrm{H}_{2} \mathrm{SO}_{4}$ forms from $\mathrm{SO}_{2}$ and $\mathrm{OH}$, and the majority of $\mathrm{OH}$ sources are the photochemical production of ozone and water under ultraviolet (UV) radiation, nighttime nucleation from this process is not possible. However, in contrast to the current prevailing assumption that aerosol nucleation takes place only during the daytime and typically from sulfuric acid, many observations indicate efficient formation of new particles in night-time. For example, Hermann et al (2003) observed frequent ultrafine particles at night in a large fraction of aerosol samples in the subtropical and midlatitude tropopause regions. Mauldin et al (2003) observed $\mathrm{H}_{2} \mathrm{SO}_{4}$ and ultrafine particles at night over the Pacific Ocean. Observations made in and near orographic clouds by Wiedensohler et al (1997) and Meters et al (2005) also showed night-time nucleation events. Observations by Lee et al (2008) indicate new particle formation during the night-time in the troposphere under low condensation sinks. The continuous ground-based measurements in Tumbarumba, Australia also indicate night-time new particle formation in the clean environment (Lee et al 2008). Rissler et al (2006) and Russell et al (2007) present instances of new particle formation during nighttime takes place in a wide range of geographical locations. Lee et al (2008) have suggested that convection can bring higher concentrations of aerosol precursors and insoluble organic compounds from lower altitudes and contribute to new particle formation in the upper troposphere. Brown et al (2006) have suggested that $\mathrm{SO}_{2}$ conversion by night-time oxidants (e.g., $\mathrm{NO}_{3}$ ) to $\mathrm{H}_{2} \mathrm{SO}_{4}$ is also possible, in polluted plumes where sulfur and nitrogen oxides are abundant. O'Dowd et al (2002) and Bonn and Moortgat (2003) have hinted that the low volatility condensable organic compounds might possibly generate new particles even in the absence of $\mathrm{H}_{2} \mathrm{SO}_{4}$. These organic compounds can form via ozone or $\mathrm{NO}_{3}$ in the absence of UV and $\mathrm{OH}$ during the night-time. Our observations also suggest that low background aerosol concentration and high ion concentration can trigger new particle formation process via ion nucleation.

We propose that during dissipation stage of thunderstorm when ion concentration increases more than an order due to corona discharges, the new particle formation can occur by ion nucleation process. Williams (2009) and Williams and Heckman (1993) have suggested that corona current can be a dominant contributor for global electric circuit other than lightning. Williams and 


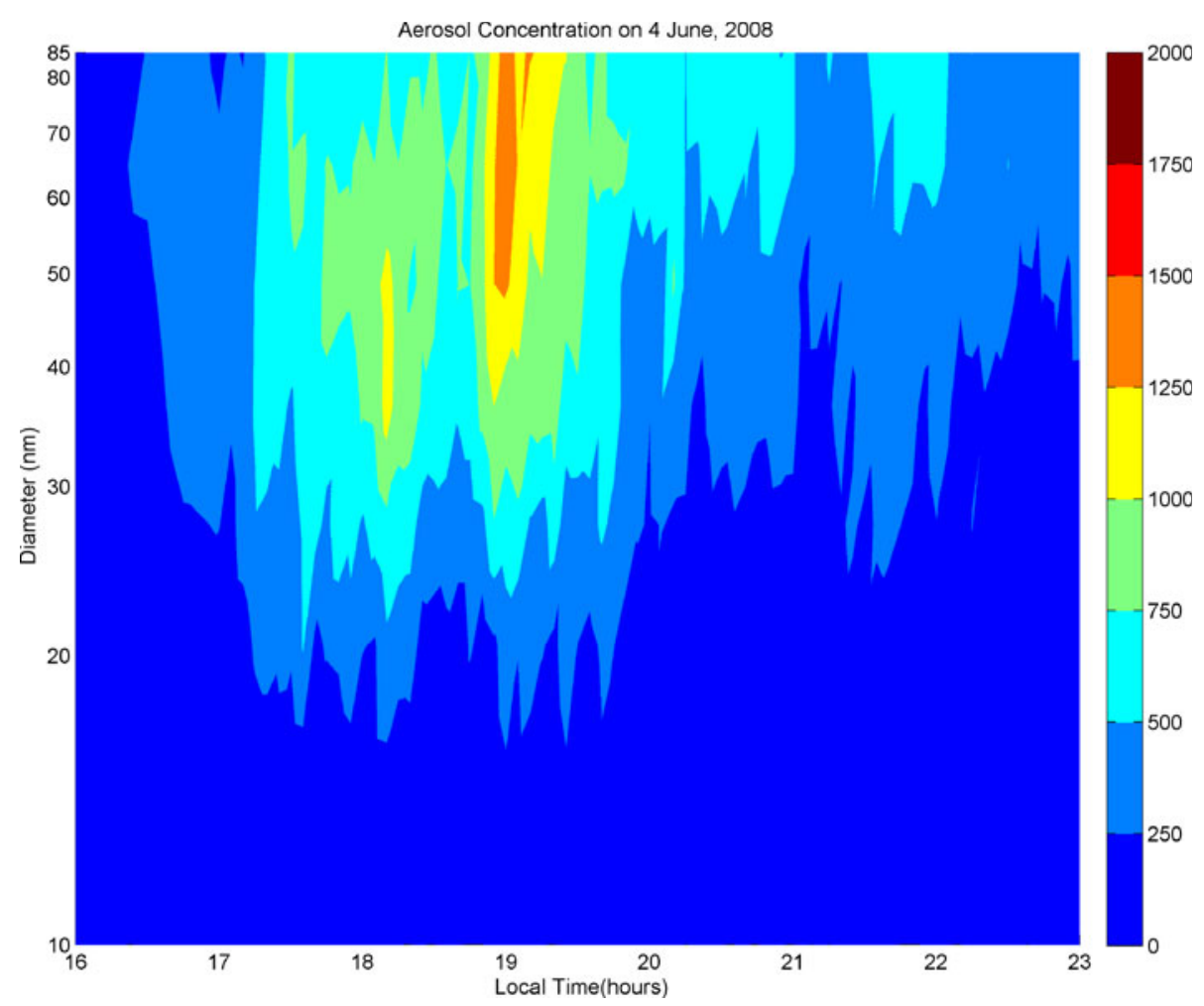

Figure 4. Same as in Figure 3 but on June 4, 2008.

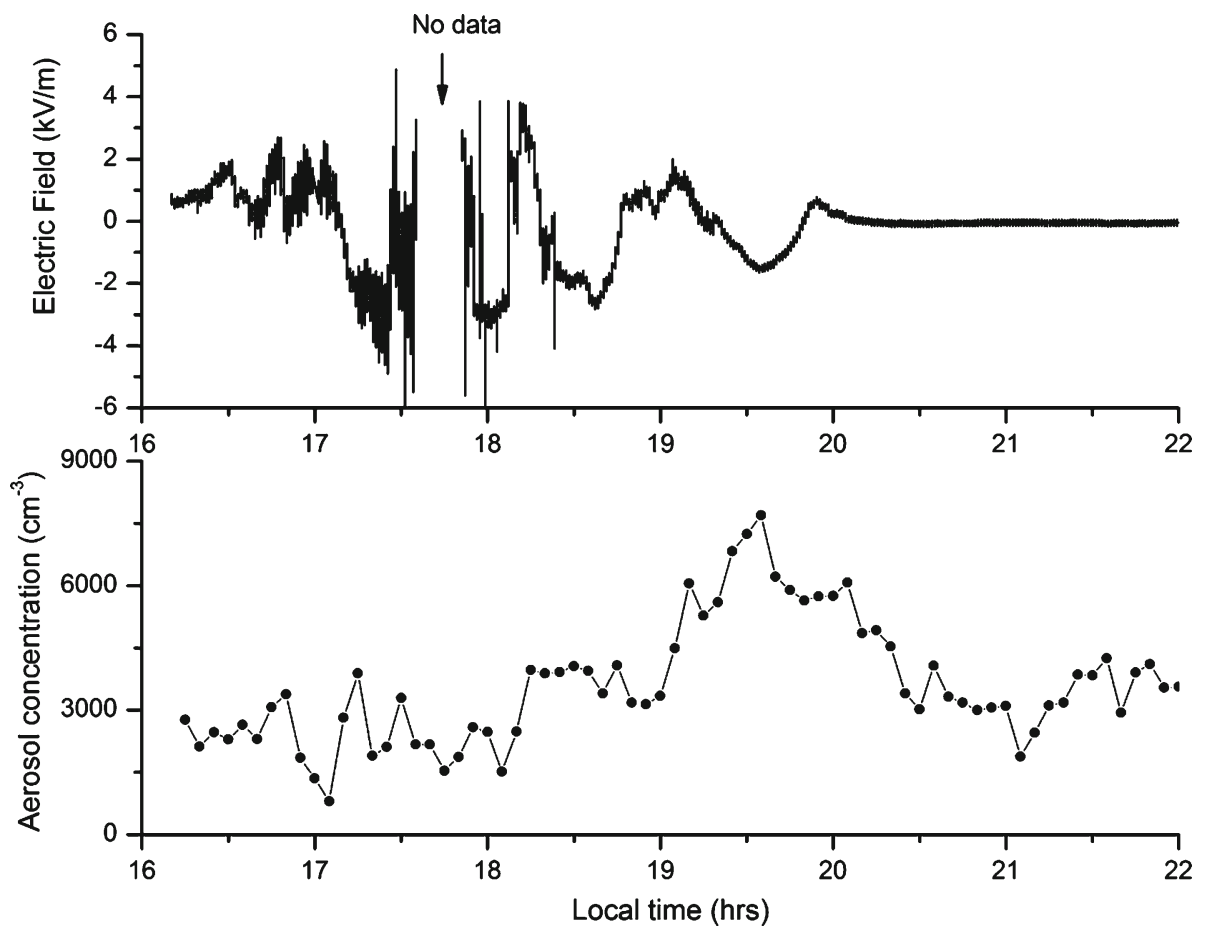

Figure 5. Variations of (a) electric field, and (b) concentration of aerosols of size below 50 nm diameter on May 22, 2008.

Heckman (1993) have shown that the deep clouds over tropical continents can be sufficiently electrified to produce corona current at earth's surface even though only some of them can produce light- ning. Corona currents release unipolar ions into the atmosphere. Therefore, we propose that new particle formation by ion nucleation during process of corona discharges can contribute significantly to 
the new particle formation over tropical continent. Our observations also suggest that unipolar ions released into the atmosphere by corona discharges may be more favourable for ion nucleation process and for subsequent growth of new particles.

As far as our knowledge, it is for the first time that new particle formation during dissipation stage of thunderstorm in unipolar ion environment has been reported. However, study of more number of such cases is required, not only to estimate the contribution of this process for global aerosol concentration but also to assess the role of corona produced ions in changing the aerosol sizedistribution beneath a thunderstorm. We agree that lack of measurements of ions in different categories may cast doubt about our conclusions; however, increase in ion concentration during dissipation stage of thunderstorm is a well known phenomena (Standler and Winn 1979; Standler 1980; Livingston and Krider 1978; Krider and Musser 1982; Pawar and Kamra 2009) and it supports our conclusions.

\section{Acknowledgements}

The measurements reported here were conducted during the Inhouse Intensive Observation Campaign (IIOC) conducted by Indian Institute of Tropical Meteorology, (IITM), Pune, during AprilMay 2008. The authors thank the Director, IITM and Dr Devara, coordinator of IIOC for their support during this campaign. One of the authors (VG) thanks Department of Science and Technology, Government of India for research grants.

\section{References}

Arnold F 2008 Atmospheric ions and aerosol formation; Space Sci. Rev. 137 225-239.

Ayers G P, Gillett R W and Gras J L 1980 On the vapor pressure of sulfuric acid; Geophys. Res. Lett. 7 433-436.

Bonn B and Moortgat G K 2003 Sesquiterpene ozonolysis: Origin of atmospheric new particle formation from biogenic hydrocarbons; Geophys. Res. Lett. 30(11) 1585, doi: 10.1029/2003GL017000.

Brown S S et al 2006 Variability in nocturnal nitrogen oxide processing and its role in regional air quality; Science $\mathbf{3 1 1}$ $67-70$.

Dickinson R E 1975 Solar variability and the lower atmosphere; Bull. Am. Meteorol. Soc. 56 1240-1248.

Enghoff M B and Svensmark H 2008 The role of atmospheric ions in aerosol nucleation - a review; Atmos. Chem. Phys. 8 4911-4923.

Hamed A, Joutsensaari J, Mikkonen S, Sogacheva L, Dal Maso M, Kulmala M, Cavalli F, Fuzzi S, Facchni M C, Decesari S, Mircea M, Lehtinen K E J and Laaksonen A 2007 Nucleation and growth of new particles in Po Valley, Italy; Atmos. Chem. Phys. 7 355-376.
Harrison R G and Aplin K L 2001 Atmospheric condensation nuclei formation and high-energy radiation; J. Atmos. Sol.-Terr. Phys. 63 1811-1819.

Harrison G R and Stephenson D B 2006 Empirical evidence for a nonlinear effect of galactic cosmic rays on clouds; Proc. Royal. Soc. 462 1221-1233.

Hermann M, Heintzenberg J, Wiedensohler A, Zahn A, Heinrich G and Brenninkmeijer C A M 2003 Meridional distributions of aerosol particle number concentrations in the upper troposphere and lower stratosphere obtained by Civil Aircraft for Regular Investigation of the Atmosphere Based on an Instrument Container (CARIBIC) flights; J. Geophys. Res. 108(D3) 4114, doi: 10.1029/2001JD001077.

Hirsikko A, Bergman T, Laakso L, Dal Maso M, Riipinen I, Hõrrak U and Kulmala M 2007 Identification and classification of the formation of intermediate ions measured in boreal forest; Atmos. Chem. Phys. 7 201-210.

Kamra A K and Pawar S D 2007 Evolution of lightning in an isolated hailstorm of moderate size in the tropics; J. Geophys. Res. 112 D20205.

Knutson E O and Whitby K T 1975 Accurate measurement of aerosol electric mobility moments; J. Aerosol Sci. 6 453-460.

Kousaka Y, Okuyama K and Adachi M 1985 Determination of the size distribution of ultrafine aerosol particles using a differential mobility analyzer; Aerosol Sci. Technol. 4 209-225.

Krider E P and Musser J A 1982 Maxwell currents under thunderstorms; J. Geophys. Res. 87 11,171-11,176.

Kulmala M and Kerminen V-M 2008 On the formation and growth of atmospheric nanoparticles; Atmos. Res. 90 $132-150$.

Kulmala M, Vehkamki H, Petaja T, Dal Maso M, Lauri A, Kerminen V M, Birmili W and McMurry P 2004 Formation and growth rates of ultra fine atmospheric particles: A review of observations; J. Aerosol Sci. 35 $143-176$.

Kulmala M, Petäjä T, Mönkkönen P, Koponen I K, Dal Maso M, Aalto P P, Lehtinen K E J and Kerminen V-M 2005 On the growth of nucleation mode particles: source rates of condensable vapour in polluted and clean environments; Atmos. Chem. Phys. 5 409-416.

Laakso L, Mäkelä J M, Pirjola L and Kulmala M 2002 Model studies on ion-induced nucleation in the atmosphere; J. Geophys. Res. 107 4427-4445.

Laaksonen A, Talanquer V and Oxtoby D W 1995 Nucleation: Measurements, theory, and atmospheric applications; Ann. Rev. Phys. Chem. 46 489-524.

Lee S H, Reeves J M, Wilson J C, Hunton D E, Viggiano A A, Miller T M, Ballenthin J O and Lait L R 2003 Particle formation by ion nucleation in the upper troposphere and lower stratosphere; Science 301 1886-1889.

Lee S-H, Young L-H, Benson D R, Suni T, Kulmala M, Junninen H, Campos T L, Rogers D C and Jensen J 2008 Observations of nighttime new particle formation in the troposphere; J. Geophys. Res. 113 D10210, doi: 10.1029/2007JD009351.

Livingston J M and Krider E P 1978 Electric fields produced by Florida thunderstorms, J. Geophys. Res. 83 385-401.

Mamakos A, Ntziachristos L and Samaras Z 2007 Diffusion broadening of DMA transfer functions. Numerical validation of Stolzenburg model; Aerosol Sci. 38 747-763.

Mauldin R L III et al 2003 Highlights of $\mathrm{OH}, \mathrm{H}_{2} \mathrm{SO}_{4}$, and methane sulfonic acid measurements made aboard the NASA P-3B during transport and chemical evolution over the Pacific; J. Geophys. Res. 108(D20) 8796, doi: 10.1029/2003JD003410. 
Meters S, Galgon D, Schwirn K, Nowak A, Lehmann K, Massling A, Wiedensohler A and Wieprecht W 2005 Evolutions of particle concentration and size distribution observed upwind, inside and downwind hill cap clouds at connected flow conditions during FEBUKO; Atmos. Environ. 39 4233-4245.

Murugavel P and Chate D M 2009 Generation and growth of aerosols over Pune, India; Atmos. Environ. 43(4) $820-828$.

O'Dowd C D, Aalto P, Hämeri K, Kulmala M and Hoffmann T 2002 Atmospheric particles from organic vapors; Nature 416 497-498.

O'Dowd C D, Yoon Y J, Junkerman W, Aalto P P, Kulmala M, Lihavainen H and Viisanen Y 2007 Airborne measurements of nucleation mode particles I: Coastal nucleation and growth rates; Atmos. Chem. Phys. 7 1491-1501.

Pawar S D and Kamra A K 2009 The Maxwell 310 current density characteristics below isolated thunderstorms in tropics; J. Geophys. Res. 114 D04208 1-12.

Rabeony H and Mirabel P 1987 Experimental study of vapor nucleation on ions; J. Phys. Chem. 91 1815-1818.

Rissler J A, Vestin A, Swietlicki E, Fisch G, Zhou J, Artaxo P and Andreae M O 2006 Size distribution and hygroscopic properties of aerosol particles from dry-season biomass burning in Amazonia; Atmos. Chem. Phys. 6 471-491.

Russell L M, Mensah A A, Fischer E V, Sive B C, Varner R K, Keene W C, Stutz J and Pszenny A A P 2007 Nanoparticle growth following photochemical a- and b-pinene oxidation at Appledore Island during International Consortium for Research on Transport and Transformation/ Chemistry of Halogens at the Isles of Shoals 2004; J. Geophys. Res. 112 D10S21, doi: 10.1029/2006JD007736.

Standler R B 1980 Estimation of corona currents beneath thunderclouds; J. Geophys. Res. 85 4541-4544.
Standler R B and Winn W P 1979 Effects of coronae on electric field beneath thunderstorms; Quart J. Roy. Meteorol. Soc. 105 285-302.

Stolzenburg M R, McMurry P H, Sakurai H, Smith J N, Mauldin III R L, Eisele F L and Clement C F 2005 Growth rates of freshly nucleated atmospheric particles in Atlanta; J. Geophys. Res. 110 D22S05, doi: 10.1029/2005JD005935.

Vehkamäki H, Dal Maso M, Hussein T, Flanagan R, Hyvärinen A, Lauros J, Merikanto J, Mönkkönen $\mathrm{P}$, Pihlatie M, Salminen K, Sogacheva L, Thum T, Ruuskanen T, Keronen P, Aalto P, Hari P, Lehtinen K and Kulmala M 2004 Atmospheric particle formation events at Värriö measurement station in Finnish Lapland 1998-2002; Atmos. Chem. Phys. 4 2015-2023.

Wiedensohler A et al 1997 Night-time formation and occurrence of new particles associated with orographic clouds; Atmos. Environ. 31 2545-2559.

Wilson C T R 1895 The effect of Röntgen's Rays on cloudy condensation; Proc. Royal. Soc. London 59338 339.

Williams E R 2009 The global electrical circuit: A review; Atmos. Res. 91 140-152.

Williams E R and Heckman S J 1993 The local diurnal variation of cloud electrification and the global diurnal variation of negative charge on the Earth; J. Geophys. Res. 98 5221-5234.

Wu Z, Hu M, Liu S, Wehner B, Bauer S, Massling A, Wiedensohler A, Petäjä T, Dal Maso M and Kulmala M 2007 New particle formation in Beijing: Statistical analysis of a 1-year data set; J. Geophys. Res. 112 D09209, doi: 10.1029/2006JD007406.

Yu F 2006 From molecular clusters to nanoparticles: Second332 generation ion-mediated nucleation model; Atmos. Chem. Phys. 6 5193-5211. 